Л. Б.-Ж. Максанова, В. Д. Шаралдаева, А. М. Андреева. Правовые основы государственно-частного партнерства для развития экологического туризма ...

Научная статья

УДК 334.7

DOI 10.18101/2304-4446-2020-4-111-117

\title{
ПРАВОВЫЕ ОСНОВЫ ГОСУДАРСТВЕННО-ЧАСТНОГО ПАРТНЕРСТВА ДЛЯ РАЗВИТИЯ ЭКОЛОГИЧЕСКОГО ТУРИЗМА НА ОСОБО ОХРАНЯЕМОЙ ПРИРОДНОЙ ТЕРРИТОРИИ
}

( ) Максанова Людмила Бато-Жаргаловна

доктор экономических наук, доцент, старший научный сотрудник, Байкальский институт природопользования СО РАН

Россия, 670047, г. Улан-Удэ, ул. Сахьяновой, 8

lmaksanova@yandex.ru

\section{(C) Шаралдаева Виктория Дамдиновна}

кандидат биологических наук, доцент,

Восточно-Сибирский государственный университет технологий и управления

Россия, 670013, г. Улан-Удэ, ул. Ключевская, 40в

sharvd@mail.ru

(C) Андреева Алёна Михайловна

аспирант,

Байкальский институт природопользования СО РАН

Россия, 670047, г. Улан-Удэ, ул. Сахьяновой, 8

anelmy@mail.ru

Благодарность: исследование выполнено при финансовой поддержке РФФИ в рамках научного проекта № 20-010-00665.

Аннотация. Стратегия развития туризма в РФ на период до 2035 г. поставила целью повышение туристической привлекательности особо охраняемых природных территорий и их превращение в точки роста для развития местных экономик. Одним из альтернативных решений для достижения этой цели является государственно-частное партнерство (ГЧП). В данной статье анализируются правовые условия использования механизмов ГЧП для создания объектов инфраструктуры экологического туризма на особо охраняемых природных территориях (ООПТ). При проведении исследования использованы аналитический, сравнительный методы, а также выполнен экспертный опрос специалистов, обладающих профессиональными компетенциями в сфере развития туризма, природопользования, ООПТ и управления проектами ГЧП. На основе анализа норм законодательства в сфере ГЧП выявлено, что действующим законодательством не определена роль ООПТ как особого участника государственно-частного партнерства, отсутствуют нормы о возможности передачи частному партнеру или концессионеру объектов инфраструктуры, находящихся под управлением федеральных государственных бюджетных учреждений, коими являются ООПТ. По результатам исследования сформулированы предложения по совершенствованию правового регулирования, разработке соответствующих механизмов и процедур привлечения инвестиций на ООПТ в рамках ГЧП.

Ключевые слова: особо охраняемые природные территории, государственно-частное партнерство, законодательство, концессия. 
Для цитирования

Максанова Л. Б.-Ж., Шаралдаева В. Д., Андреева А. М. Правовые основы государственно-частного партнерства для развития экологического туризма на особо охраняемой природной территории // Вестник Бурятского государственного университета. Экономика и менеджмент. 2020. № 4. С. 111-117.

Особо охраняемые природные территории во всем мире вносят значительный вклад в охрану природы и являются основой для развития экотуризма [7]. По оценкам исследователей, более восьми миллиардов человек посещают наземные охраняемые территории по всему миру [10]. Доля российских охраняемых природных территорий в мировом объеме экотуристического обслуживания ничтожно мала, например общее число посетителей ООПТ федерального значения в 2018 г. составило лишь 3,5 млн чел. ${ }^{1}$ Слабый сервис и отсутствие инфраструктуры в российских национальных парках являются основными причинами их невысокой популярности и не позволяют создать комфортное общественное пространство для разных категорий туристов [5].

Новый общественный запрос к отдыху на природе, к оздоровлению, активному досугу и туризму, особенно после снятия ограничений на поездки по стране в условиях коронавирусной инфекции, ставит задачу качественного инфраструктурного обустройства ООПТ и создания разнообразных продуктов и услуг, совместимых с целями сохранения природы. В этом контексте в условиях ограниченного финансирования ООПТ перспективным инструментом для формирования инфраструктуры экологического туризма в пространстве туристских аттракторов рассматривается государственно-частное партнерство [6, 8].

Как показывает опыт других стран, когда в рамках ГЧП в туризме объединяются в официальное либо неофициальное добровольное партнерство заинтересованные стороны с различными целями, опытом и ресурсами, это повышает туристическую привлекательность региона, а также производительность и эффективность туризма в целом [1]. В последние годы некоторые российские регионы, перенимая передовой зарубежный опыт, все активнее используют ГЧП при создании объектов туристской инфраструктуры. На начало 2020 г. доля таких проектов в их общем количестве составляла 3,55\% [9]. Региональные практики демонстрируют широкий диапазон бизнес-моделей в зависимости от туристических объектов и форм реализации ГЧП/МЧП, но при этом нет примеров использования ГЧП в национальных парках и прилегающих к ним территориях. Несмотря на рост исследований процессов формирования методологии и механизмов ГЧП на ООПТ в рамках создания условий для развития экологического туризма, взаимодействие ООПТ и предпринимательского сообщества все еще является недостаточно изученным [2, 3].

В данной работе анализируются правовые условия использования механизмов ГЧП для создания объектов инфраструктуры экологического туризма на землях природоохранных территорий. Работа опирается на федеральные и региональные

\footnotetext{
${ }^{1}$ Популярность экотуризма в России растет. В 2019 году количество посетителей ООПТ превысило 8 млн человек [Электронный ресурc]. URL: http://www.mnr.gov.ru/ press/news/populyarnost_ekoturizma_v_rossii_rastet_v_2019_godu_kolichestvo_posetiteley_o opt_prevysilo_8_mln_che (дата обращения: 10.09.2020).
} 
Л. Б.-Ж. Максанова, В. Д. Шаралдаева, А. М. Андреева. Правовые основы государственно-частного партнерства для развития экологического туризма ...

законодательные, нормативные правовые документы, научные статьи зарубежных и отечественных ученых, результаты собственных исследований авторов, посвящённых проблематике теории и практики ГЧП. При проведении исследования использованы аналитический, сравнительный методы, а также выполнен экспертный опрос специалистов, обладающих профессиональными компетенциями в сфере развития туризма, природопользования, ООПТ и управления проектами ГЧП. В качестве экспертов выступили 34 специалиста, в числе которых представители науки и образования (25\%), региональных (9\%) и муниципальных органов (21\%) власти, ООПТ (18\%), турбизнеса (15\%), общественных организаций $(12 \%)$.

Как показывает практика, привлечение за счет механизмов ГЧП внебюджетных источников позволяет государству развивать инфраструктуру и объекты непроизводственных отраслей. Основная часть опрошенных экспертов $(73,5 \%)$ считает, что: 1) ГЧП в сфере туризма в российской практике недостаточно распространено; 2) ООПТ являются сложными площадками для реализации проектов ГЧП в части создания объектов туристической инфраструктуры коммерческого характера (средства размещения, предприятия питания, розничной торговли, пр.; 3) для успешной реализации проектов ГЧП на ООПТ требуется совершенствование правового регулирования, разработка соответствующих механизмов и процедур привлечения инвестиций на ООПТ в рамках ГЧП, а также изучение потенциальных угроз, конфликтов и возможных моделей реализации проектов ГЧП в сфере экологического туризма на таких территориях.

На фоне развития разнообразных моделей партнерства государства и частного сектора в сфере туризма задачи развития туристической инфраструктуры ООПТ могут быть решены в рамках применения специального законодательства о ГЧП, которое включает Федеральный закон от 13 июля 2015 г. № 224-Ф3 «О государственно-частном партнерстве, муниципально-частном партнерстве в Российской Федерации и внесении изменений в отдельные законодательные акты Российской Федерации» (далее - 224-Ф3 о ГЧП), Федеральный закон от 21 июля 2005 г. № 115-Ф3 «О концессионных соглашениях» (далее - 115-ФЗ о КС) ${ }^{1}$.

Авторы поддерживают мнение сторонников применения концессии [2] как наиболее предпочтительного для использования на ООПТ механизма ГЧП, который предполагает возврат в государственную собственность созданных в рамках концессионных соглашений объектов инфраструктуры и земельных участков под ними. Это положение исключает изъятие земельных участков из состава ООПТ и позволяет без изменения существующих границ решать экономические вопросы использования уникальных природных ресурсов охраняемых территорий.

\footnotetext{
${ }^{1}$ Рекомендации по реализации проектов государственно-частного партнерства Лучшие практики [Электронный pecypc]. URL: https://www.economy.gov.ru/material/ file/cd482f73c03b658fa97a2d844c7e39d9/metodic2018.pdf (дата обращения: 10.09.2020).
} 
Сравнительный анализ положений 224-ФЗ о ГЧП и 115-ФЗ о КС в сфере туризма

\begin{tabular}{|c|c|c|}
\hline Положения & 224-ФЗ о ГЧП & 115-Ф3 о КС \\
\hline $\begin{array}{c}\text { Стороны } \\
\text { Соглашения }\end{array}$ & $\begin{array}{l}\text { Публичный партнер: РФ, субъект } \\
\text { РФ, муниципальное образование. } \\
\text { Частный партнер: российское } \\
\text { юридическое лицо (ЮЛ) }\end{array}$ & $\begin{array}{l}\text { Концедент: РФ, субъект РФ, } \\
\text { муниципальное образование. } \\
\text { Концессионер : индивидуальный } \\
\text { предприниматель, российское ЮЛ, } \\
\text { иностранное ЮЛ, действующие без } \\
\text { образования ЮЛ по договору } \\
\text { простого товарищества два и более } \\
\text { указанных ЮЛ. }\end{array}$ \\
\hline Объект Соглашения & $\begin{array}{c}\text { Закрытый перечь объектов, ст. } 7 \\
\text { Закона о ГЧП }\end{array}$ & $\begin{array}{c}\text { Более широкий перечень объектов, ст. } \\
4 \text { Закона о КС }\end{array}$ \\
\hline $\begin{array}{c}\text { Минимальный срок } \\
\text { действия } \\
\text { Соглашения }\end{array}$ & Не менее 3 лет & Нет \\
\hline $\begin{array}{c}\text { Существенные } \\
\text { условия }\end{array}$ & 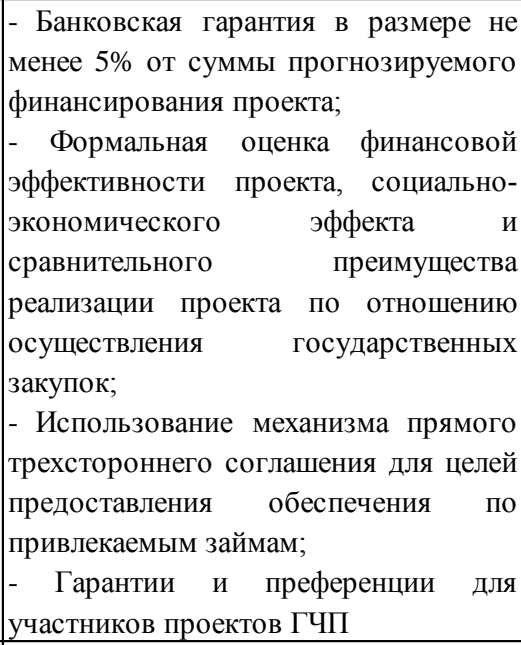 & 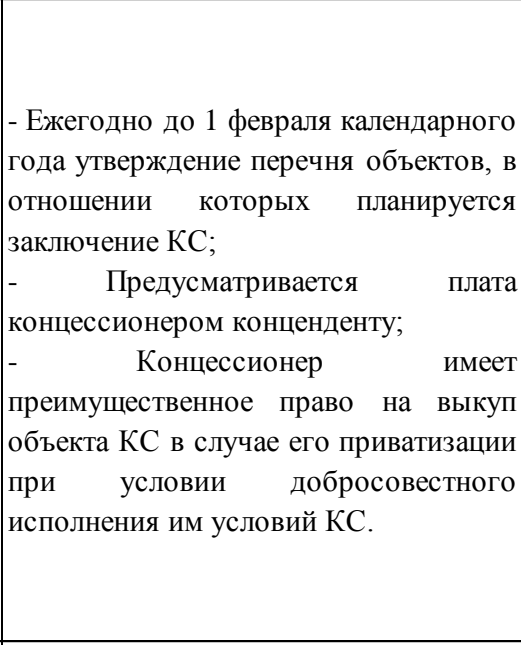 \\
\hline $\begin{array}{c}\text { Право } \\
\text { собственности на } \\
\text { объект Соглашения }\end{array}$ & Возникает у частного партнера & $\begin{array}{c}\text { Всегда сохраняется за публичной } \\
\text { стороной (концедентом) }\end{array}$ \\
\hline $\begin{array}{l}\text { Осуществление } \\
\text { эксплуатации }\end{array}$ & $\begin{array}{c}\text { Может быть возложено на публичного } \\
\text { партнера }\end{array}$ & Всегда возлагается на концессионера \\
\hline $\begin{array}{c}\text { Наличие } \\
\text { подзаконных актов }\end{array}$ & $\begin{array}{c}14 \text { нормативных правовых актов, } \\
\text { необходимых для реализации норм } \\
\text { Закона о ГЧП. }\end{array}$ & $\begin{array}{c}3 \text { нормативных правовых акта, } \\
\text { необходимых для реализации норм } \\
\text { Закона о КС. }\end{array}$ \\
\hline
\end{tabular}

Составлено авторами на основании ${ }^{1}$.

\footnotetext{
${ }^{1}$ Рекомендации по реализации проектов государственно-частного партнерства Лучшие практики [Электронный pecypc]. URL: https://www.economy.gov.ru/material/ file/cd482f73c03b658fa97a2d844c7e39d9/metodic2018.pdf (дата обращения: 10.09.2020).
} 
Л. Б.-Ж. Максанова, В. Д. Шаралдаева, А. М. Андреева. Правовые основы государственно-частного партнерства для развития экологического туризма ...

В настоящее время специальное законодательство о ГЧП претерпевает определенные изменения для привлечения частных инвестиций в строительство и развитие туристической инфраструктуры в национальных парках и на территориях, прилегающих к ним. Подготовленные нормы, закрепляющие признание объектов рекреационной инфраструктуры национальных парков объектами соглашений о ГЧП/МЧП, позволят администрациям национальных парков заключать подобные соглашения. Наряду с изменениями законодательства о ГЧП требуется актуализировать положения федерального законодательства по ООПТ, а также в сфере земельных, имущественных отношений в части включения понятия ГЧП на особо охраняемых природных территориях и определения роли ООПТ как особого участника государственно-частного партнерства.

В связи с особым статусом ООПТ необходимо принятие отдельного порядка выбора инвестора (где должны быть четко и детально прописаны требования), порядка подписания соглашения о ГЧП, информационно-методическое сопровождение процесса реализации ГЧП-проектов на ООПТ, детальный контроль их реализации с учетом допустимой экологической нагрузки.

Передача имущества федерального государственного бюджетного учреждения по соглашению, будь то концессионное или ГЧП, должна непременно сопровождаться закреплением его прав, гарантирующих сохранение государственной собственности на объекты национальных парков, в отношении которых установлен запрет на отчуждение из государственной собственности.

В ходе опроса выявлено, что эксперты считают возможным, используя механизмы ГЧП, создание таких объектов инфраструктуры, как экологические тропы $(85,3 \%)$; объекты размещения $(79,4 \%)$; кемпинги $(73,5 \%)$; смотровые площадки $(67,6 \%)$; пункты проката оборудования, экипировки, средств передвижения и др.; лечебно-оздоровительные объекты $(61,8 \%)$; сувенирные мастерские $(58,8 \%)$; культурно-просветительские объекты (55,9\%); объекты питания (52,9\%). Половина экспертов считает возможным строительство в рамках ГЧП автостоянок, автозаправочных комплексов, спортивно-развлекательных объектов, объектов розничной торговли. Каждый пятый эксперт отметил создание специальных тематических объектов: центры растениеводства и биологического разнообразия; музеи-библиотеки (сбор, сохранение, анализ и передача информации); центры подготовки гидов, спасателей (совместно с МЧС); объекты научноисследовательского назначения; центры мониторинга совместно с учебными заведениями; центры сортировки, переработки и утилизации мусора; любые объекты, которые сами по себе не предполагают получение прибыли, направлены на сохранение экологического баланса и несут социальную функцию. Как видим, круг предлагаемых объектов довольно широкий и разноплановый, поэтому предстоит большая работа с определением перечня объектов инфраструктуры экологического туризма, создание которых возможно с использованием механизмов ГЧП на землях ООПТ.

По мнению экспертов, разработка и реализация проектов ГЧП на ООПТ зависит от возможностей и готовности администраций ООТП заниматься этой работой. И может оказаться, что большинство национальных парков окажутся неготовыми к такому ходу событий вследствие неопределенности границ рекреационных зон, в которых могут реализовываться проекты ГЧП по созданию инфра- 
структуры экологического туризма, отсутствия методического опыта сопровождения разработки и реализации проектов ГЧП, несогласованности интересов между организациями, уполномоченными управлять ресурсами, хозяйствующими субъектами, местным населением.

Решение этих вопросов имеет определяющее значение для реализации Указа Президента Российской Федерации от 7 мая 2018 г. № 204 «О национальных целях и стратегических задачах развития Российской Федерации на период до 2024 года» в части выполнения федерального проекта «Сохранение биологического разнообразия и развитие экологического туризма». Потребуется разработка как системы правовых мер, соответствующих механизмов и процедур привлечения инвестиций на ООПТ в рамках ГЧП, так и возможных моделей реализации проектов ГЧП в сфере экологического туризма на таких территориях.

\section{Литература}

1. Об особо охраняемых природных территориях: федеральный закон от 14 марта 1995 г. № 33-Ф3 // Доступ из справ.-правовой системы «КонсультантПлюс».

2. Андреева А. М., Максанова Л. Б.-Ж., Харитонова О. Б. Государственно-частное партнерство на особо охраняемых природных территориях: зарубежный опыт // Вестник Национальной академии туризма. 2020. № 3 (55). С. 51-52.

3. Воротников А. М., Доронин Н. С. Государственно-частное партнерство - механизм развития экологического туризма на особо охраняемых территориях Арктической зоны Российской Федерации // Менеджмент и бизнес-администрирование. 2019. № 4. C. 87-96.

4. Галисултанова Л. И. Перспективы государственно-частного партнерства в отношении биосферных полигонов заповедников // Марийский юридический вестник. 2016. № 4(19). С. 6-8.

5. Государственно-частное партнерство в сфере туризма. Лучшие практики субъектов Российской Федерации / под ред. Л. Б.-Ж. Максановой. М.: РЭУ им. Г. В. Плеханова, 2018. 104 с.

6. Джанджугазова Е. А. Развитие экологического туризма на территории национальных парков России // Российские регионы: взгляд в будущее. 2019. Т. 6, № 2. С. 5262.

7. Жалсараева Е. А. К вопросу о возможности применения государственночастного партнерства для интеграции особо охраняемых природных территорий в региональную экономику // Горизонты экономики. 2017. № 1(34). С. 25-29.

8. Максанова Л. Б.-Ж., Гусева Е. Ю., Оюнгэрэл Б., Аюшеева С. Н., Мункуева В. Д. Международный опыт развития экотуризма: страновая специфика и общие подходы // Вестник Московского государственного областного университета. Сер. Естественные науки. 2019. № 2. С. 54-66.

9. Салова Л. В. Основы государственно-частного партнерства в процессе рационального использования ресурсов особо охраняемых природных территорий // Российское предпринимательство. 2016. Т. 17, № 16. С. 1991-2002. doi: 10.18334/rp.17.16.36487

10. Шаралдаева В.Д., Максанова Л.Б.-Ж., Шарафанова Е.Е. Государственно-частное партнерство в сфере развития туризма в России: состояние и особенности // Известия Санкт-Петербургского государственного университета. 2020. № 3(123). С. 79-86.

11. Balmford A., et al. Walk on the Wild Side: Estimating the Global Magnitude of Visits to Protected Areas // PLoS Biology. 2015. № 13 (2). P. 1-6. 


\section{PPP LEGAL FRAMEWORK FOR DEVELOPMENT OF ECOTOURISM IN PROTECTED AREAS}

Lyudmila B.-Zh. Maksanova

Dr. Sci. (Econ.), A/Prof., Senior Researcher,

Baikal Institute of Nature Management SB RAS

8 Sakhyanovoy St., Ulan-Ude 670047, Russia

lmaksanova@yandex.ru

Viktoria D. Sharaldaeva

Cand. Sci. (Biol.), A/Prof.,

East-Siberian State University of Technology and Management

40v Klyuchevskaya St., Ulan-Ude 670013, Russia

sharvd@mail.ru

Alena M. Andreeva

Research Assistant,

Baikal Institute of Nature Management SB RAS

8 Sakhyanovoy St., Ulan-Ude 670047, Russia

anelmy@mail.ru

Abstract. Strategy for tourism development in the Russian Federation through to 2035 is aimed at increasing the tourist attractiveness of protected areas and their transformation into growing points for local economies. Public-private partnership is one of the alternative decisions to achieve this goal. The article analyzes the legal conditions for implementation of public-private partnership mechanisms in creation of infrastructure facilities for ecotourism in protected areas. In the study we have used analytical and comparative methods, carried out an expert survey of professionals with competencies in the field of tourism development, nature management, protected areas and PPP project management. The analysis of legislation in the field of PPP has revealed that the current legislation doesn't define the role of protected areas as a special participant in public-private partnerships, and there are no regulations on the transferring infrastructure facilities to a private partner or concessionaire under control of federal state budgetary institutions, including protected areas. Based on the results of the study, we have formulated proposals for improvement of legal regulation, development of appropriate mechanisms and procedures for attracting investments in protected areas within the framework of PPP.

Keywords: protected areas; public-private partnership (PPP); legislation; licence to operate.

Статья поступила в редакцию 22.10.2020; одобрена после рецензирования 30.10.2020; принята к публикации 30.10.2020. 